of Westland Aircraft, Ltd. "The rotor has two blades made of spruce and balsa with laminated birch heel pieces and stainless steel sheathing for the leading edge. All the wood components are prepared and glued up in one operation using 'Aerodux 185' resorcinol resin adhesive. The glued-up block is eut longitudinally to make a pair of blades." Other Ciba adhesives and products are involved in processing these blades, and the illustrations included in these Notes show clearly not only the vital stages in manufacture, but also the highly skilled human element involved in their individual achievement. It is further stated that: "Main blades are made for Bell and Hiller machines, the method being essentially similar to that already described for tail rotor blades". A final note is made that one of the main advantages of using wood blades instead of metal is that repairs and reconditioning of them are greatly facilitated. Damaged portions are soon cut away, timber replacements accurately fitted, and it is claimed that owing to the excellent qualities of the 'Aerodux 185' adhesive, these repairs ". . . result in blades which are in all respects equal to new".

\section{Control of Liquids in Industry}

WATER, acids, alkalis, syrup, petroleum products, oil for oil burners, paints, liquid gases, milk, beer, wine and detorgents are a few of the many liquids which have to be controlled and measured. In many ways, liquids are more convenient to deal with than solids. They can be stored in tanks and drums, and transported from place to place by pipelines, along which the liquid flows by gravity or is pumped. Because of the ease with which a liquid can be moved about, a solid may often be mixed with it to form a slurry which can be treated much like a liquid; there are proposals for the long-distance transport of coal by pipeline in this manner. But it is not always necessary to mix the solid with a liquid: a finely divided material through which air is pumped can be made to flow like a liquid, and this technique-'fluidization'-is growing in importance in industry. In most firms, the handling of liquids (and powders) involves measuring out and mixing known quantities of the appropriate materials, and the subsequent filling of containers or bottles. Quite often in smaller firms this is done by dipping with measuring vessels or by manual operation of a tap. Such a method results in either loss of time, if the measurement is to be done accurately, or loss of material because of inexactness. Manual methods lead to a loss of time, money and production. Substantial savings can result from a small outlay on instrumentation for control of flow and level, and these different methods are well described in a recent publication issued by the Department of Scientific and Industrial Research (Automation at Low Cost, 3: Control of Liquids. Pp. 12. London: Information Division, Department of Scientific and Industrial Research, 1963).

\section{Acoustics Research}

Amplivox, LTD., is to provide a research bursary in the Physics Department of the Imperial College of Seience and Technology under the supervision of Dr. R. W. B. Stephens. The research will be concerned with the transmission of sound and vibrations in a variety of materials, and the behaviour of sub-miniature mechanical-acoustical systems embodying such materials. Very little work has been carried out in this field, and the lack of information is a serious limiting factor in the design of very small hearing aids. A better understanding of the problem should benefit deaf people, as it is believed that the acoustic performance of very small and inconspicuous hearing aids can be substantially improved.

\section{University News:}

Aberdeen

Dr. HazLeton MrrkiL, Department of Mathematics and Astronomy, Dartmouth College, Hanover, New
Hampshire, has been appointed lecturer in mathematies from September 1 for one year.

\section{Cambridge}

THE following have been elected into fellowship at Churchill College: Title A, Dr. F. R. Allchin, of Queens' College, University lecturer in Indian studies. Title $C$, Prof. I. H. Mills, of Trinity College, professor of medicine; Prof. H. A. Turner, Montague Burton professor of industrial relations. Title $F$ (overseas fellowships), Prof. G. Wald, professor of biology at Harvard University. Prof. F. Sondheimer, Royal Society research professor in organic chemistry, has been pre-elected into fellowship from July 1, 1964 .

\section{London}

DR. J. ChATT, director of the Unit of Nitrogen Fixation of the Agricultural Research Council, has been appointed to the chair of inorganic ehemistry tenable at Queen Mary College. Prof. K. Stewartson, professor of applied mathematics in the University of Durham, has been appointed to the Goldsmid chair of mathematics tenable at University College. Dr. N. Joels, lecturer in physiology, Middlesex Hospital Medical School, has been appointed to the readership in physiology tenable at St. Bartholomew's Hospital Medical College. The title of professor of electrical engineering has been conferred on Dr. J. Brown, in respect of his post at University College.

Sheffield

At a meeting of the Council held on December 20 the title of the Department of Electrical Fngineering was altered to "Department of Electronic and Electrical Engineering". Dr. L. M. Birt was appointed senior lecturer in biochemistry.

\section{Announcements}

THE degree of Doctor of Science (honoris causa) has been conferred on Dr. W. Railston, a scientific adviser to the Department of Technical Co-operation, by the University of Ceylon. Dr. Railston is responsible for scientific and technical advice to the Department of Technical Co-operation on assistance relating to projects in India, Pakistan and Ceylon, and on other matters, including nuclear energy.

Applications are invited by the British Mycological Society from members of the Society and heads of departments for grants to enable students of mycology to attend the Society's autumn foray and plant pathology field meeting to be held in 1964. Further information can be obtained from the Secretary of the Society, Plant Breeding Institute, Maris Lane, Trumpington, Cambridge.

THE Laboratory of the Government Chemist of the Department of Scientific and Industrial Research has now moved to new premises in Cornwall House, Stamford Street, London, S.E.1. The new telephone number is WATerloo 7900 .

AN international symposium on "Organic Reaction Mechanisms" will be held at University College, Cork, during July 20-24. Further information can be obtained from the General Secretary, the Chemical Society, Burlington House, London, W.1.

THE one hundred and first meeting of the British Pharmaceutical Conference will be held in Edinburgh during September 14-18. Further information can be obtained from W. K. Fitch, Pharmaceutical Society of Great Britain, 17 Bloomsbury Square, London, W.C.l.

THE fourth international congress on "Surface Active Substances", organized by the Comité International de la Detergence, will be held in Brussels during September 7-12. Further information can be obtained from the Secretariat Général du IVme Congres International de la Detergence, 49 Square Marie-Louise, Brussels 4. 